\title{
Three new species of Phyllodesmium Ehrenberg (Gastropoda: Nudibranchia: Aeolidoidea), and a revised phylogenetic analysis
}

\author{
ELIZABETH MOORE ${ }^{1} \&$ TERRENCE GOSLINER $^{2}$ \\ Department of Invertebrate Zoology, California Academy of Sciences, 55 Music Concourse Drive, San Francisco, CA 94118, U.S.A. \\ E-mail: ${ }^{\text {bmoore@ }}$ calacademy.org; ${ }^{2}$ tgosliner@calacademy.org
}

\begin{abstract}
Mimicry and camouflage are an important protective measure for nudibranch gastropods. In the genus Phyllodesmium, species have evolved elaborate morphological traits that allow them to be very cryptic among their coral prey. In this study, three new species of Phyllodesmium from the Philippine islands are described: Phyllodesmium tuberculatum $\mathbf{n}$. sp., Phyllodesmium pinnatum n. sp., and Phyllodesmium karenae n. sp. The first two, $P$. tuberculatum and $P$. pinnatum, are highly cryptic on their prey and were already included in a phylogenetic analysis by Moore \& Gosliner (in press). The third species (P. karenae) is newly discovered and has not yet been observed on its prey. A revised morphological phylogenetic analysis is presented that includes this species, as well as three species that were recently described by Burghardt et al. (2008a). In addition, the current analysis excludes a previously presumed new species, which was referred to as Phyllodesmium sp. 3 by Moore \& Gosliner (in press), because it was determined to be an abnormally preserved specimen of $P$. jakobsenae. The newest species, P. karenae, has an unusual dental morphology, no branching of the digestive diverticula, and no zooxanthellae present in the cerata. It fell into the basal part of the phylogeny, as was expected based on previous general trends showing the derived status of symbiotic species. The three species described by Burghardt et al. (2008a), two of which are associated with xeniid corals, appear in a highly unresolved part of the phylogeny including other xeniid-associated species. One of these, $P$. koehleri, is not associated with xeniid corals but is indistinguishably intermixed within this clade. Decay analysis values for most nodes are low, indicating that support for this topology is lacking. It is recommended that the addition of less ambiguous characters, such as genetic sequences, be considered for further phylogenetic analyses.
\end{abstract}

Key words: zooxanthellae, symbiosis, evolution, biodiversity

\section{Introduction}

Within various groups of mollusks, mimicry and camouflage are vital adaptations that increase the likelihood of survival (Gosliner \& Behrens 1990; Gosliner 2001). For nudibranch gastropods, which have lost the protective shell of their snail relatives, adaptations that minimize predator encounters are important. In aeolid nudibranch groups, the ability to preserve, and later use, undischarged nematocysts from cnidarian prey deters would-be predators (Kepner 1943; Edmunds 1966). In other groups, bright aposematic coloration serves as an advertisement of toxicity, while others might opt to avoid a conflict altogether by becoming nearly invisible to their prey (Gosliner \& Behrens 1990; Gosliner 2001).

In the genus Phyllodesmium, mimicry has evolved beyond color similarity and camouflage to a unique level of disguise. Species in this genus show diverse and remarkable variations in external morphology that, when set against the backdrop of their coral prey, confer near invisibility to passing predators. In addition, species in this genus have evolved a unique symbiosis with coral-derived zooxanthellae, which they preserve out of consumed coral tissue and show different levels of effective symbiosis (Burghardt et al. 2005; Burghardt et al. 2008b; Burghardt \& Wägele 2006). This is not altogether unusual for opisthobranchs, 
however, within this particular group of symbiotic nudibranchs are varying degrees of symbiotic advancement (Kempf 1984; Rudman 1991). Species in Phyllodesmium can range from totally aposymbiotic (without symbionts) to intimately symbiotic, where nudibranchs might survive for months on only the sugars produced by the algae. It is thought that some species even cull their populations of zooxanthellae in order to maximize the benefit from their symbionts. This variability makes this genus an excellent place to study diverse morphology and the evolution of symbiosis (Moore \& Gosliner in press).

Species of Phyllodesmium with more advanced symbioses often have notable branching in the digestive tissue within their cerata and dorsum (Rudman 1991). This expands the opportunity for the zooxanthellae to be exposed to sunlight and maximizes the amount of symbionts that can be retained (Rudman 1981, 1991). Despite the usefulness of housing vast populations of zooxanthellae, it has been suggested that digestive gland branching may have preceded the evolution of symbiosis with zooxanthellae, and that it may have been an adaptation to enhance camouflage among host corals (Rudman 1991). This scenario suggests that host mimicry in this group may have led to a morphological adaptation that facilitated the exploitation of a unique resource specifically associated with their symbiotic prey. The use of this resource may have then provided a new niche for a diverse array of morphological forms to emerge.

While not all species of Phyllodesmium are symbiotic, similarly, not all species closely mimic their host corals. The most extraordinarily cryptic of all species within the genus seem to be associated with xeniid corals. Some species, such as P. jakobsenae Burghardt \& Wägele, 2004, and P. hyalinum Ehrenberg, 1831, even burrow into the stalk of their respective corals, with only the cerata exposed, appearing like coral polyps (field observation; Burghardt \& Wägele 2004; Rudman 1981). Other species, like P. rudmani, have evolved such thorough camouflage that their cerata are nearly indiscernible from Xenia polyps when nestled among the host coral (field observation).

Because of the cryptic nature of many species within this genus, new species are still being discovered and remain to be described. In this study, three new species of Phyllodesmium are described (Fig.1), with a discussion of their phylogenetic placement based on analysis of 32 morphological characters.

\section{Methods}

In March of 2008, new specimens of Phyllodesmium were collected from Batangas Province, Luzon Island, Philippines and preserved for identification and analysis. During this trip, one additional undescribed species of Phyllodesmium was collected, as well as two new specimens of a previously documented undescribed species. Specimens were preserved in either $10 \%$ formalin for proper preservation of anatomical structures, or preserved entirely in $95 \%$ ethanol for later molecular study. Prior to preservation of any specimen in formalin, a tissue sample was taken from the animal and preserved in $95 \%$ ethanol for later molecular study.

Upon return to the California Academy of Sciences, dissections were completed, and drawings of anatomical structures were accomplished using a Nikon SMZ-U binocular microscope with drawing tube. For specimens in which the cerata were not already transparent, ceratal tissues were stained and cleared to show branching of digestive gland ducts and determine the presence of zooxanthellae. Staining and clearing was done by adding a small amount of acid fuchsin to $75 \%$ ethanol until a magenta colored solution was produced. Tissues were added to the solution for several minutes, until tissues were stained a bright pink color. The tissues were then placed into $95 \%$ ethanol for 5-10 minutes to fully dehydrate the tissues. Once dehydrated, the tissues were placed into xylene until they became clear, and internal structures were visible. Tissues were then placed in Permount on a microscope slide. A coverslip was used to press the tissue into place and the slide was allowed to dry for 2-3 days. An Olympus CH30 compound microscope was then used to visualize ceratal structures.

Buccal mass structures were dissected and cleaned by placing them in a $10 \% \mathrm{NaOH}$ solution for $4-10$ hours, and then prepared for scanning electron microscopy. The jaws and radula were separated and cleaned of any remaining tissue. They were then placed on glass cover slips, air-dried, and then mounted on a stainless 
steel stub. Structures were then coated with gold/palladium using a Denton Desk II vacuum sputter coater. Scanning electron micrographs were produced by a LEO 1450 VP scanning electron microscope. Specimens and dissected structures were deposited at the California Academy of Sciences in the Invertebrate Zoology Department collection (CASIZ).

In addition to the collection of specimens of new species during the field excursion to the Philippines, two specimens of $P$. jakobsenae were also collected. These specimens were used to compare the anatomy of $P$. sp. 3 (Moore \& Gosliner in press) with $P$. jakobsenae, which had not previously been available for study. It was determined that $P$. sp. 3 is in fact a specimen of $P$. jakobsenae and not a new species. This specimen had a large penial papilla, a seemingly unique fringe of tissue surrounding the foot, and an unusual ceratal arrangement. However, these traits were inadequate for the creation of an additional species, and were attributed to abnormal swelling and shrinking during specimen preservation, incomplete reproductive description of $P$. jakobsenae, and morphological variation within the species. With this new information, the addition of the previously mentioned undescribed species, and newly published descriptions of three more species, P. lizardensis Burghardt, Schrödl \& Wägele, 2008, P. lembehensis Burghardt Schrödl \& Wägele, 2008, and P. koehleri Burghardt Schrödl \& Wägele, 2008, the morphological tree was revised. Using the same character matrix as constructed by Moore \& Gosliner (in press), $P$. sp. 3 was excluded from the phylogeny $(P$. jakobsenae was already represented on the tree). The newly found undescribed species, here described as $P$. karenae, as well as P. lizardensis, P. lembehensis, and P. koehleri were all coded according to their morphological descriptions and added to the morphological matrix for analysis.

The newly added characters were then entered into MacClade 4 software (Maddison \& Maddison 2005) to generate an updated matrix (Table 2). As was done previously, Godiva quadricolor (Barnard, 1927) and Favorinus japonicus Baba, 1949 were used as outgroups. Characters and character states were unchanged from Moore \& Gosliner (in press). Parsimony analysis was conducted using a heuristic search with 1000 replicates of starting trees using random stepwise additions in PAUP 4.0 (Swofford 2002). All uninformative characters were excluded from the analysis. Decay analysis was performed using a heuristic search in PAUP for all trees $\geq$ the shortest trees obtained.

\section{Family Facelinidae Odhner 1939}

\section{Genus Phyllodesmium Ehrenberg, 1831}

Type species: Phyllodesmium hyalinum Ehrenberg, 1831, by monotypy

\section{Phyllodesmium tuberculatum n. sp.}

(Figures 1A, 2A-C, 3A, 4, 5A,B, 6A)

Synonymy: Phyllodesmium sp. 2 Gosliner Behrens \& Valdés, 2008: 385.

Material examined: Holotype: CASIZ 177520, not dissected, molecular sample taken from foot, 0-17m depth, Twin Rocks, Mabini, Batangas Province, Luzon Island, Philippines, 21 March 2008, T.M. Gosliner et al. Paratype: CASIZ 106547, dissected, 0-16m depth, Twin Rocks, Mabini, Batangas Province, Luzon Island, Philippines, 19 April 1996, T.M. Gosliner. Paratype: CASIZ 177663, dissected, buccal mass not found, reproductive system poorly preserved, molecular sample taken from foot, 0-16m depth, Sepok, Batangas Province, Luzon Island, Philippines, 19 April 2008, T.M. Gosliner.

Geographic range. This species is known only from southern Luzon Island, Philippines (this study).

Etymology. The species is named after the rounded tubercles present on the cerata of these animals. 


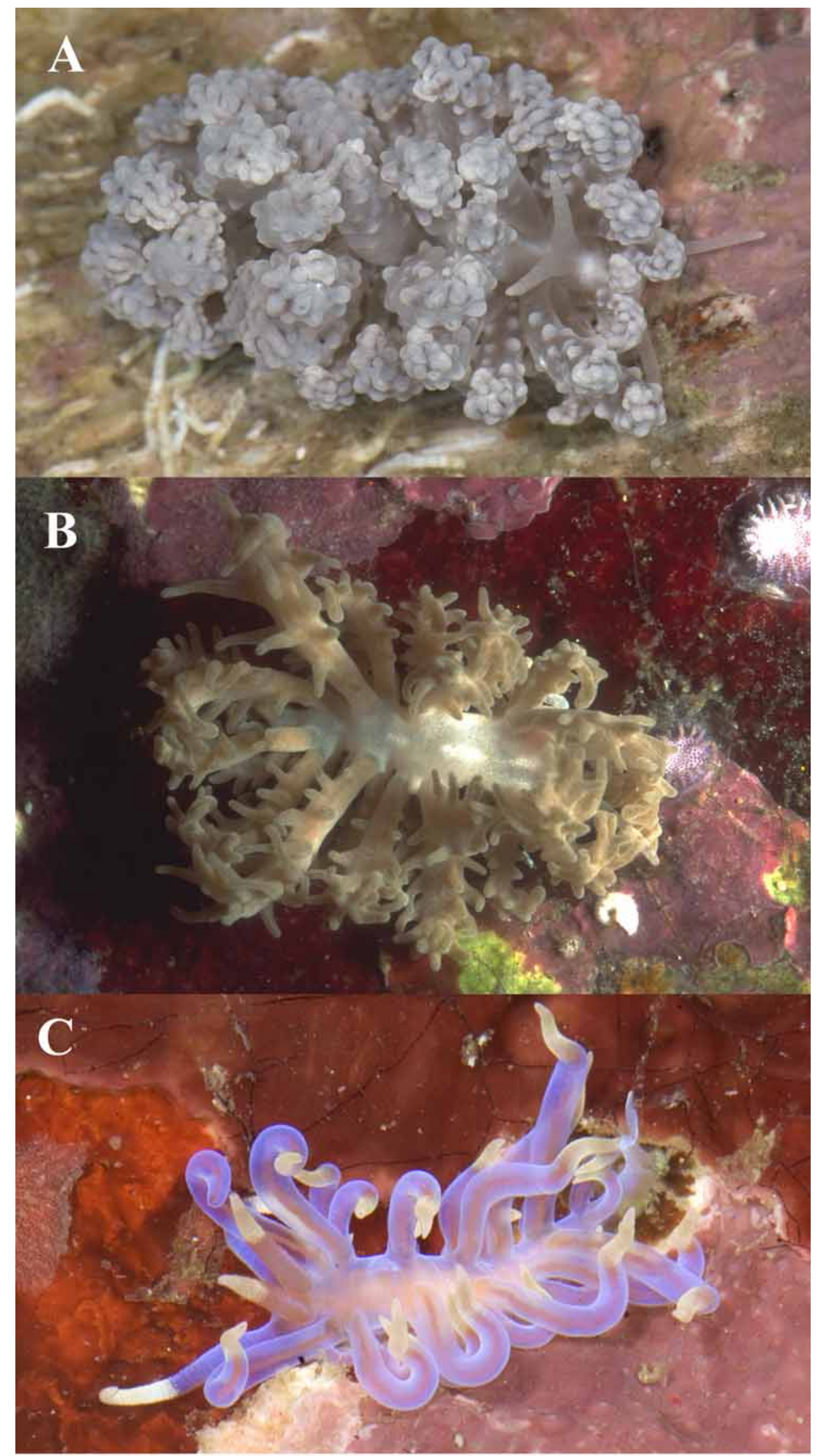

FIGURE 1. Living animals A. Phyllodesmium tuberculatum n. sp. B. Phyllodesmium pinnatum n. sp. C. Phyllodesmium karenae n. sp. 

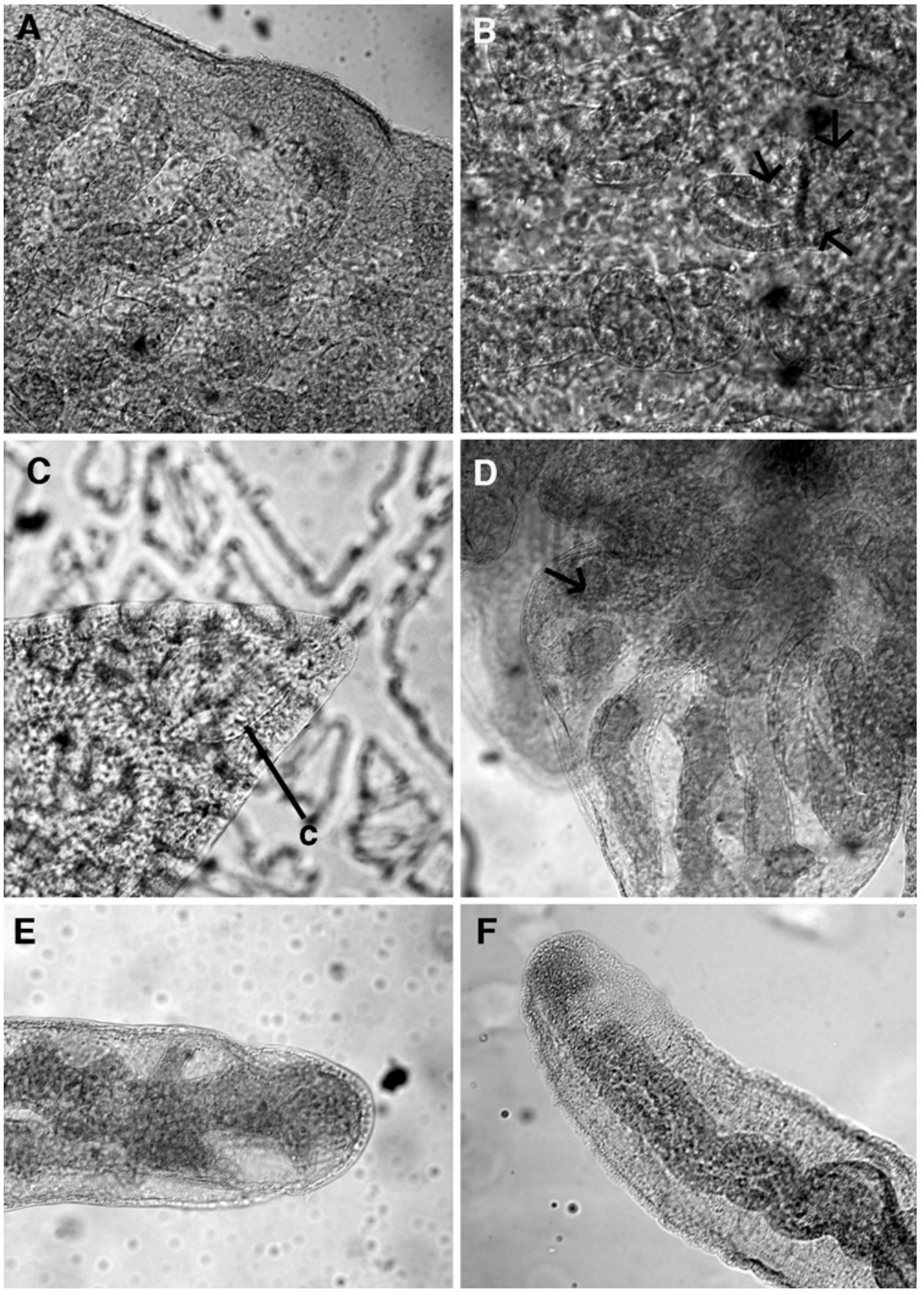

FIGURE 2. A. Phyllodesmium tuberculatum n. sp., micrograph of ceras showing secondary branching. B. Phyllodesmium tuberculatum n. sp., ceratal ducts with zooxanthellae shown by arrows. C. Phyllodesmium tuberculatum n. sp., ceratal apex showing cnidosac devoid of nematocysts, c-cnidosac. D. Phyllodesmium pinnatum n. sp., micrograph of ceras showing secondary branching, zooxanthellae shown by arrows. E. Phyllodesmium pinnatum n. sp., ceratal apex showing absence of cnidosac. F. Phyllodesmium karenae n. sp., ceratal apex showing undivided digestive gland duct and absence of cnidosac.

Natural history. This species is found on coral and rubble near its prey species, a soft coral in the genus Anthelia.

Description. Color and external morphology. Living animals (Fig. 1A) are elongate, with cerata obscuring the majority of the dorsum and mantle. The preserved specimens examined were $14 \mathrm{~mm}$ (CASIZ 177520) and 13mm (CASIZ 106547) in length. Specimen CASIZ 177663 was poorly preserved and not measured. The anterior portion of the foot margin is broad with moderately tentacular foot corners while the 
posterior end tapers to an elongate point. The body of the living animal, including rhinophores, oral tentacles, cerata and foot are predominantly a bluish gray color. Large, thick, and somewhat dorso-ventrally flattened cerata cover the dorsum with smaller cerata at the lateral margins of the mantle. Large cerata are covered nonuniformly by round, nodulose tubercles that are also bluish gray in color. The tubercles tend to aggregate on, but are not exclusive to, the narrow margins and ends of the cerata, which terminate bluntly with a hardly visible tip. When the animal is preserved, the distal-most point on each ceras is marked by a small but distinctive cnidosac that lacks nematocysts (Fig. 2C). The smallest cerata, near the posterior end of the body and along the mantle margin, have no tubercles and appear cylindrical and smooth with a slightly pointed tip. The digestive gland visibly branches throughout the cerata, with visible secondary, and possibly tertiary, branches that extend to the surface of each ceras (Fig. 2A). Zooxanthellae are present in great numbers in the digestive tissue of the largest cerata (near the dorsum) (Fig. 2B), but not in the small, laterally-located cerata. Zooxanthellae also appear to be located outside the digestive tissue near the surface of each ceras. The ceratal arrangement consists of arches and rows, with arches consisting of two rows of cerata forming in the anterior ceratal groups and rows in the most posterior groups (Fig. 3A). The precardiac cerata are grouped into one arch on each side of the body containing approximately 15 cerata. On the arms of the precardiac arches there are double rows of cerata, but on the dorsal curve of each arch there is a single row. The genital aperture is located between the arms of the precardiac arch on the right side of the animal, and there are separate openings for the male and female genital systems. The renal opening is situated slightly toward the posterior between the precardiac arch and the first postcardiac arch on the right side. The postcardiac cerata are grouped on both sides into arches containing approximately 13 cerata for the first two arches. These first two postcardiac arches also contain double rows on the ventral arms, but a single row of cerata on the dorsal curve of each arch. The anal papilla is located within the first postcardiac arch on the right side. The third postcardiac arch contains approximately 8 cerata and appears to be a single-rowed arch. The last three ceratal groups are curved rows containing 4, 3, and 3 cerata respectively. The rhinophores are smooth, with a somewhat wrinkled appearance and are conical in shape with blunt tips. The oral tentacles are also smooth and taper from the anterior edge of the head to bluntly pointed apices. They are approximately the same length as the rhinophores.

Reproductive System (Fig. 4). Large quantities of ovoid gonad fill the posterior portion of the specimen. The female gland mass is large and consists predominantly of the mucous gland with smaller albumen and membrane glands. The ampulla is large and curved, and it branches to the oviduct and the prostatic portion of the vas deferens. The oviduct connects to a nodulose receptaculum seminis. A second duct extends from near the base of the receptaculum seminis and joins the female glands near the albumen gland. The second branch of the ampulla connects to the vas deferens. The proximal portion is prostatic with the prostate being convoluted and prominent. The prostate increases in size until joining a large, conical-shaped, unarmed penial bulb.

Buccal Armature. The jaws are thin and coriaceous, slightly elongating posteriorly. There are six to eight slender denticles situated along the masticatory border of each jaw. Each denticle has a ribbed projection extending laterally, making them appear wing-like (Fig. 5A, B). The radula has a formula of $25 \times 0.1 .0$. The teeth are triangular in shape leading to a long and pointed primary cusp (Fig. 6A). The rib on the ventral side of each tooth extends from the posterior of the tooth to the middle of the cusp. Denticulation extends along the margin from the base of the tooth nearly to the apex. The number of denticles varies between $28-30$ per radular tooth. The denticles are slightly elongated with well-separated points that reach slightly under the edge of the tooth. Denticles at the base of the tooth are generally more defined, where denticles near the apex of the cusp become less distinct.

Remarks. Of the described species of Phyllodesmium there are five species, P. crypticum Rudman, 1981, P. hyalinum, P. lizardensis, P. lembehensis, and P. koehleri with obvious nodules on the external portions of the cerata. Phyllodesmium tuberculatum can generally be distinguished from all of these species by the notably spherical and highly raised nodules that appear upon all parts of the largest cerata. In comparison, $P$. koehleri has spine-shaped tubercles, while $P$. crypticum and $P$. hyalinum have low, often barely raised, conical 


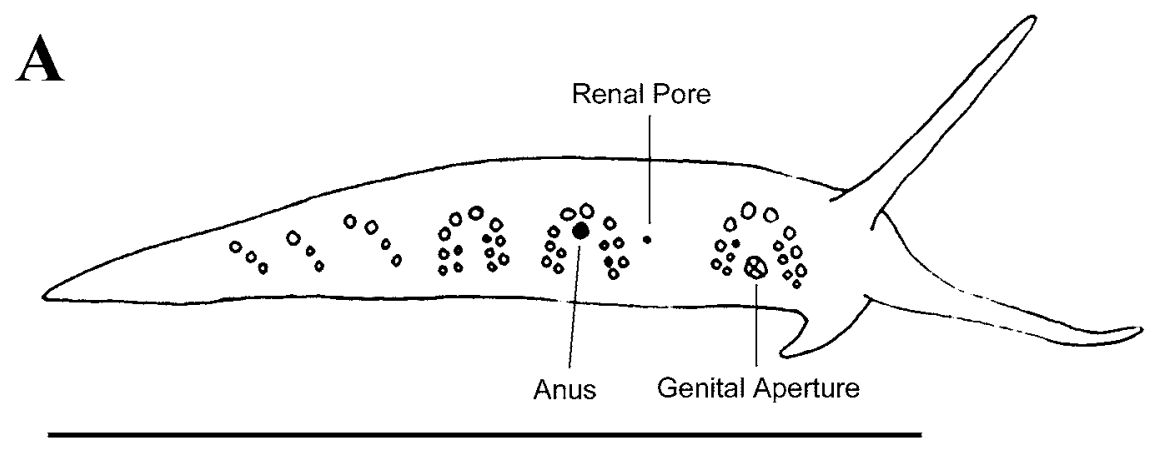

$14 \mathrm{~mm}$

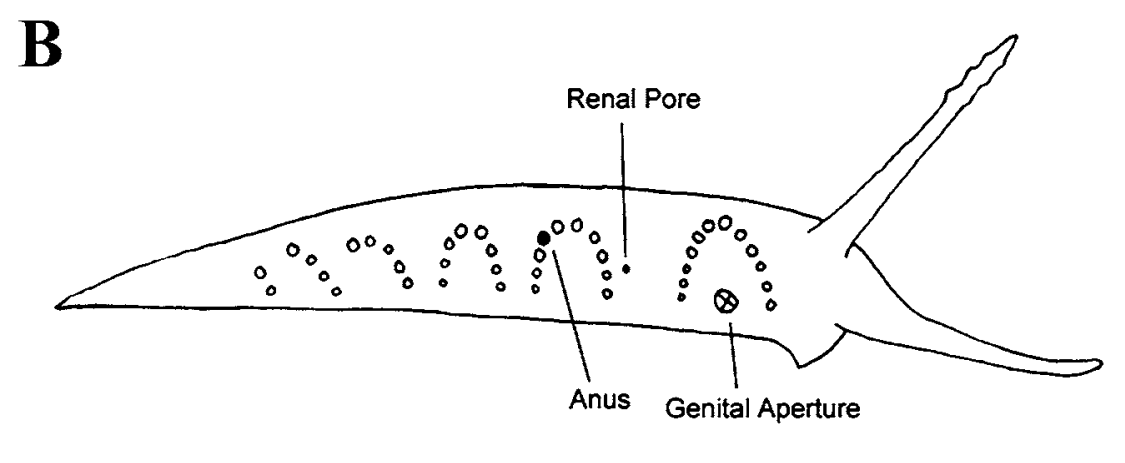

$12 \mathrm{~mm}$

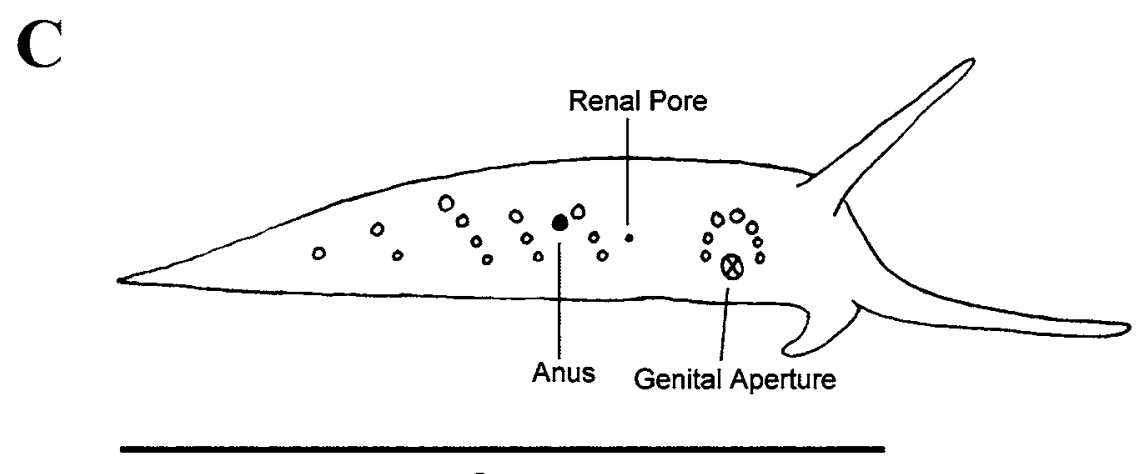

$8 \mathrm{~mm}$

FIGURE 3. Lateral view of preserved specimens showing ceratal arrangement A. Phyllodesmium tuberculatum n. sp. (CASIZ 106547). B. Phyllodesmium pinnatum n. sp. (CASIZ 179101). C. Phyllodesmium karenae n. sp. (CASIZ 177313). Scale bars represent preserved specimen length.

tubercles. Phyllodesmium lembehensis has tubercles that congregate predominantly on the margins of the flattened cerata, appearing almost like rounded serrations. Lastly, $P$. lizardensis can be distinguished from $P$. tuberculatum by the non-uniform shape of blotchy ceratal tubercles, which tend to form only on the distal third of each ceras. Of these five species, $P$. crypticum and $P$. hyalinum are perhaps most likely to be mistaken for $P$. tuberculatum. In addition to ceratal tubercles, $P$. crypticum is described as a golden brown color rather than blue-gray. Rudman (1981) described P. crypticum as a large animal, up to 60mm long, which is notably different from the smaller size of $P$. tuberculatum. In addition, the jaws of $P$. tuberculatum have 6-8 slender, evenly graded denticles. Rudman (1981) did not enumerate the denticles of $P$. crypticum, but according to the drawings, and to SEM images of a specimen from the CAS collection, they are coarse and irregular, with only 4 prominent denticles. The radular formulae are also noticeably different. Phyllodesmium tuberculatum has 25 
teeth on the radula while $P$. crypticum has 36 , and $P$. tuberculatum has 38-40 denticles per cusp, whereas $P$. crypticum has up to 30 (Rudman 1981). Phyllodesmium crypticum has a smooth receptaculum seminis and convoluted ampulla compared to the nodulose receptaculum seminis and curved ampulla in P. tuberculatum. Phyllodesmium tuberculatum differs noticeably from $P$. hyalinum in color and in the position of the anus. Phyllodesmium tuberculatum is darker in color than $P$. hyalinum, and has a more ventrally located anus compared to the unique, dorsally located anus in $P$. hyalinum. The buccal armature of these species also differ, as $P$. tuberculatum has denticulated cusps with $28-30$ denticles per tooth, while $P$. hyalinum can have up to 56 denticles per tooth.

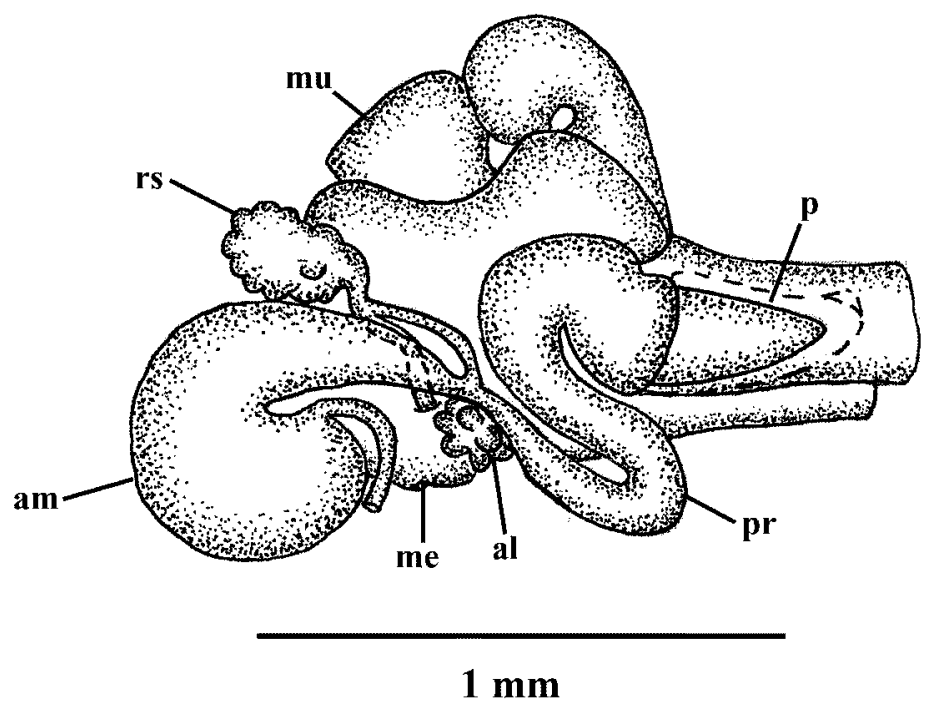

FIGURE 4. Reproductive system of Phyllodesmium tuberculatum n. sp. Abbreviations: am-ampulla, rs-receptaculum seminis, od-oviduct, vd-vas deferens, $\mathrm{p}$ - penial papilla, pr-prostate, al-albumen gland, $\mathrm{mu}-$ mucous gland, me-membrane gland.

Phyllodesmium pinnatum n. sp.

(Figures 1B, 2D,E, 3B, 5C,D, 6B, 7)

Synonymy. Phyllodesmium sp.1 Gosliner, Behrens \& Valdés, 2008: 385.

Material examined. Holotype: CASIZ 103710, not dissected, 0-34m depth, Devil's Point, Maricaban Island, Batangas Province, Luzon Island, Philippines, 24 Feb 1995, T.M. Gosliner. Paratype: CASIZ 179101, dissected, 0-34m depth, Devil's Point, Maricaban Island, Batangas Province, Luzon Island, Philippines, 24 Feb 1995, T.M. Gosliner. Paratype: CASIZ 110371, poorly preserved, molecular sample taken from foot, 0 22m depth, Arthur's Rock, Batangas Province, Luzon Island, Philippines, 22 Apr 1997, T.M. Gosliner.

Geographic range. This species is known only from Batangas Province, Luzon Island, Philippines (this study).

Etymology. The species is named after the digitate projections present on the cerata of these animals.

Natural history. Unknown. Based on the external appearance, and the location within the phylogeny, this species is likely associated with xeniid corals.

Description. Color and external morphology. Living animals (Fig. 1B) are elongate, with edges of the foot extending laterally only as far as the edge of the mantle. The three preserved specimens are $7 \mathrm{~mm}$ (CASIZ 110371), 11mm (CASIZ 103710), and 12mm (CASIZ 179101) in length. The anterior portion of the foot margin is wider than the rest of the foot, with slightly angular foot corners. The posterior end of the foot tapers to a point. The body of the living animal, including dorsum and foot, is predominantly gray in color with faint, white, oval-shaped markings on the central part of the dorsum. The cerata, oral tentacles, and rhinophores are 


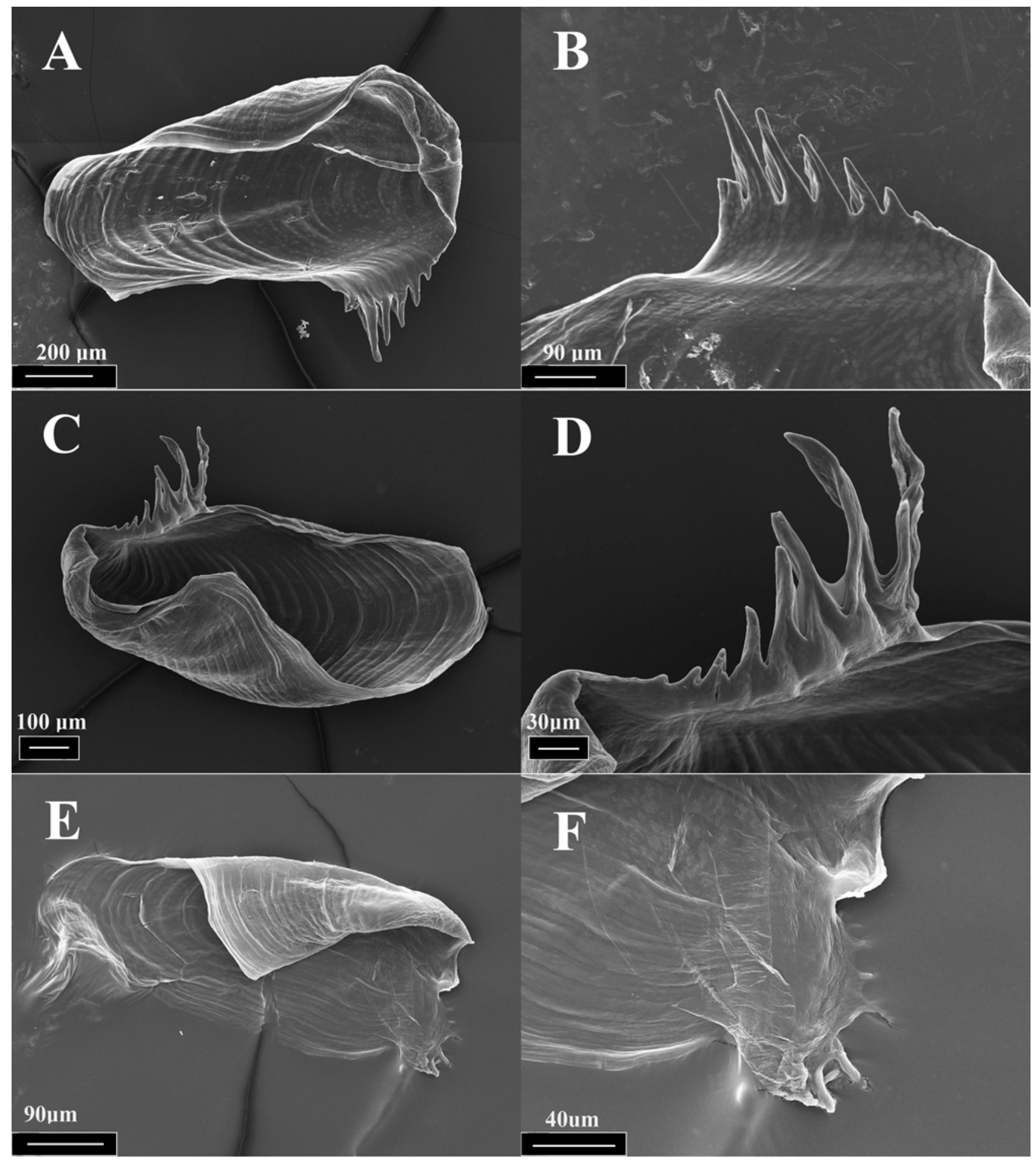

FIGURE 5. A. and B. Jaw plate and masticatory denticles of Phyllodesmium tuberculatum n. sp. (CASIZ 106547). C. and D. Jaw plate and masticatory border of Phyllodesmium pinnatum n. sp. (CASIZ 179101). E. and F. Jaw plate and masticatory denticles of Phyllodesmium karenae n. sp. (CASIZ 177313).

a slightly darker, brownish-gray color compared with the color of the dorsum. The viscera and gonad are not readily visible through the mantle tissue, but branches of the digestive diverticula can be seen through the epidermis of most cerata. Zooxanthellae are present in the digestive tissue of large cerata (near the dorsum) (Fig. 2D), but less so in the small, laterally located cerata. Zooxanthellae also appear to be located outside the digestive tissue near the epithelial surface of each ceras. The cerata are elongate and paddle-shaped, flattened dorso-ventrally, with larger cerata near the medial region of the dorsum. Each ceras has numerous, digitate 
projections that concentrate near but are not exclusive to, the margins of the flattened ceras. The digestive gland has noticeable secondary (Fig. 2D), and probably tertiary, branches within the cerata. The digestive gland extends into, and continues to branch within, the ceratal projections. The digestive gland appears slightly lighter in color than the brownish-gray of the cerata, making it just visible near the epidermal surface of each ceras. Phyllodesmium pinnatum does not appear to have the obvious, non-functional cnidosac that is characteristic of this genus (Fig. 2E). The ceratal arrangement consists of arches and rows, with arches forming in the anterior ceratal groups (Figure 3B). The precardiac cerata are grouped into one arch on each side of the body containing 11-12 cerata. The genital aperture is located between the arms of the precardiac arch, near the ventral most cerata, on the right side of the animal. The genital aperture has two openings, one for the male and female reproductive organs separately. The renal opening is situated in the interhepatic space, slightly toward the posterior between the precardiac arch and the first postcardiac arch on the right side. The postcardiac cerata are grouped on both sides into arches containing 9-10 cerata in the first arch, and 7-8 cerata in the second arch. The anal papilla is located between two cerata, in the first postcardiac arch on the right side. The third postcardiac group appears as a partial arch and contains 4-5 cerata. Two additional postcardiac ceratal groups appear as rows containing 4 and 2 cerata respectively (the most posterior cerata are extremely tiny and have few digitate projections). The rhinophores are cylindrical in shape, with very subtle bumps or wrinkles. The rhinophores are slightly longer than the oral tentacles. The oral tentacles are smooth and taper from the anterior edge of the head to pointed apices.

Reproductive System (Figure 7). Large quantities of gonad fill the posterior portion of the dissected specimen. As in most mature animals of this group, the female gland mass is large and consists predominantly of the mucous gland with smaller albumen and membrane glands. The ampulla is small relative to the other reproductive structures and has one main curve before branching to the oviduct and the prostatic portion of the vas deferens. The oviduct connects to a large, nodulose receptaculum seminis. A second duct extends from near the base of the receptaculum and joins the female gland mass near the albumen gland. The proximal portion of the vas deferens (where the second branch of the ampulla connects) is prostatic, with the prostate being highly convoluted and large, with a short, conical-shaped, unarmed penial bulb.

Buccal Armature. The jaws are thin and coriaceous. There are eight to nine denticles situated along the masticatory border of each jaw. The largest denticles are elongate, and taper to smaller, more triangular denticles along the border of the jaw (Figure 5C, D). The radula has a formula of $25 \times 0.1 .0$. The teeth (Figure 6B) are triangular in shape leading to a pointed primary cusp. Denticulation extends along the margin from the base of the tooth nearly to the apex. The number of denticles varies from 34-36 on each tooth. The denticles are slightly elongated, triangular in shape, and are well separated along the majority of the margin of the cusp. The denticles at the base of the tooth are generally more defined, and denticles near the apex of the cusp are often fused together or fused with the margin of the cusp.

Remarks. Of the described species of Phyllodesmium there are six species, P. crypticum, P. hyalinum, $P$. lembehensis, . lizardensis, $P$. koehleri, and now P. tuberculatum with obvious nodules on the external portions of the cerata. None of these species have finger-like projections on their cerata that closely resemble those on $P$. pinnatum, and they all contain a non-functional cnidosac in each ceras, which $P$. pinnatum appears to lack. In addition, the cerata of $P$. pinnatum are noticeably fewer than those of $P$. hyalinum, with only single rowed arches in the precardiac and first three postcardiac arches. Also, the denticulation along the margin of the radular teeth varies between the two. Phyllodesmium hyalinum has up to 56 denticles per tooth, and $P$. pinnatum has only 34-36 denticles. When comparing $P$. pinnatum with $P$. crypticum, the jaws of $P$. pinnatum have large, distinctive denticles where $P$. crypticum has jagged, coarse denticles. The reproductive systems are also noticeably different, where Phyllodesmium crypticum has a large, convoluted ampulla and small receptaculum seminis, while $P$. pinnatum has a greatly reduced, curved ampulla and a prominent, nodulose receptaculum seminis. Despite being externally very dissimilar, Phyllodesmium lizardensis and $P$. lembehensis can also be distinguished from P. pinnatum by their increased number of radular teeth. Phyllodesmium lizardensis is reported to have 40 denticles on the radula and P. lembehensis has 35 compared to only 25 observed in $P$. pinnatum. When comparing $P$. pinnatum with $P$. tuberculatum, the reproductive 
system of $P$. tuberculatum has a large and prominent ampulla and small receptaculum seminis. In addition to the noticeably different appearance, $P$. tuberculatum also has a slightly more elongate prostate, which further differentiates it from P. pinnatum.

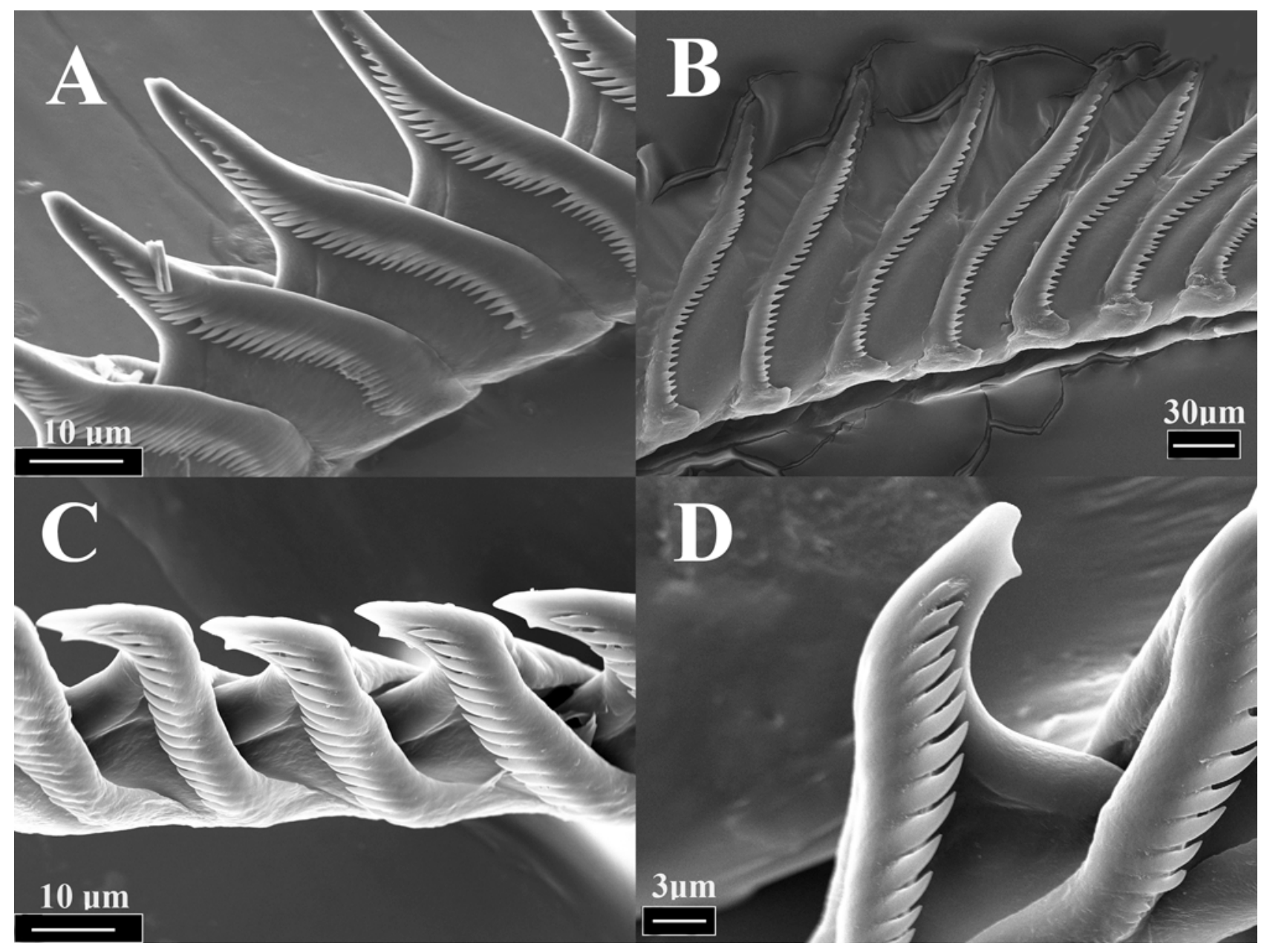

FIGURE 6. A. Radular cusps and denticles of Phyllodesmium tuberculatum n. sp. (CASIZ 106547) B. Radular cusps and denticles of Phyllodesmium pinnatum n. sp. (CASIZ 179101) C. and D. Radular cusps and denticles of Phyllodesmium karenae n. sp. (CASIZ 177313, note the ventral denticle near the apex of each cusp).

\section{Phyllodesmium karenae n. sp.}

(Figures 1C, 2F, 3C, 5E, F, 6C,D, 8)

Synonymy. Phyllodesmium sp. 7 Gosliner, Behrens \& Valdés, 2008: 390.

Material examined. Holotype: CASIZ 177313, dissected, molecular sample taken from foot, 0-17m depth, Matotonggil Rock, Mabini Batangas Province, Luzon Island, Philippines, 17 March 2008, T.M. Gosliner et al.

Geographic range. This species is known only from southern Luzon Island, Philippines (this study) and Indonesia (Gosliner et al. 2008).

Etymology. This species is named after the senior author's mother for her years of endless support and enthusiasm regarding the study of marine organisms.

Natural history. Found among sand and rocks. Prey species is unknown.

Description. Color and external morphology. Living animals (Fig. 1C) are elongate, with edges of the foot extending laterally just beyond the mantle. The preserved specimen is $8 \mathrm{~mm}$ in length. The anterior portion of the foot margin is broad with moderately tentacular foot corners while the posterior end is tapered 
to a point. The body of the living animal, including oral tentacles and foot, is predominantly transparent with a blue hue. There are no opaque markings on the dorsum and the viscera and gonad are readily visible through the mantle tissue. There are no zooxanthellae present in the epidermal tissues. The cerata are elongate, smooth, and cylindrical, with larger cerata near the medial region of the dorsum. In living animals, the apex of each ceras is curled and prehensile in appearance. The digestive gland is straight and undivided (Fig. 2F) within the cerata and is a uniform brownish-purple color. The tip of each ceras has a yellow-cream colored epithelium, which obscures the apex of the digestive duct. Otherwise the cerata are primarily transparent, with slight blue hue, and lack a distinct cnidosac and lack nematocysts. The ceratal arrangement (Fig. 3C) consists of arches and rows, with an arch forming only in the precardiac ceratal group. The precardiac cerata form a single arch on each side of the body containing 7 cerata. The genital aperture is located between the arms, and ventral to the precardiac arch on the right side of the animal. The renal opening is situated in the interhepatic space, slightly toward the posterior between the precardiac arch and the first postcardiac row on the right side. The postcardiac cerata are grouped on both sides into rows containing 3 cerata in the first two rows, and 3-4 cerata in the third row. The anal papilla is located just posterior to the first postcardiac row on the right side. The fourth and fifth postcardiac groups also appear as rows and contain 2 and 1 ceras respectively. The rhinophores are smooth, and elongate in shape and are roughly two thirds as long as the oral tentacles. The rhinophores are primarily a brownish-purple color, leading to a yellow-cream, pointed tip. The oral tentacles are smooth, and taper from the anterior edge of the head to pointed apices. They are transparent or slightly bluish basally, leading to yellow-cream tips.

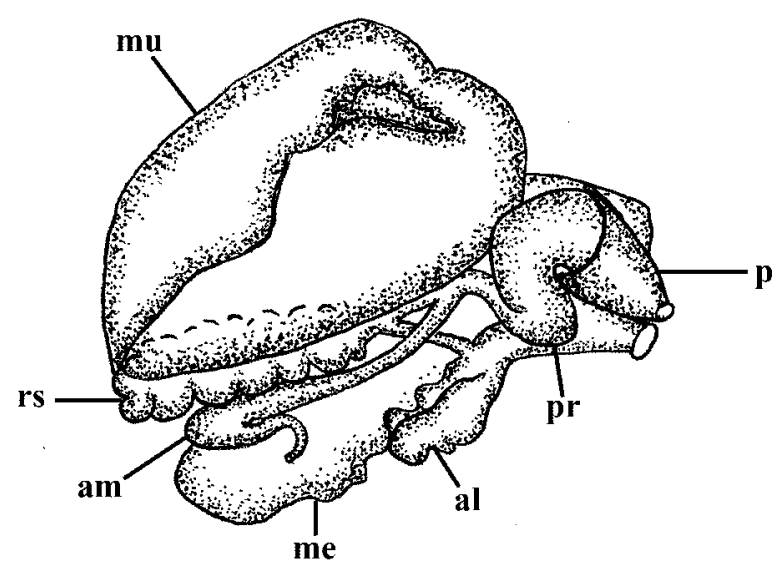

$1 \mathrm{~mm}$

FIGURE 7. Reproductive system of Phyllodesmium pinnatum n. sp. Abbreviations: am-ampulla, rs-receptaculum seminis, od-oviduct, vd—vas deferens, $\mathrm{p}$ - penial papilla, pr-prostate, al—albumen gland, mu—mucous gland, me-membrane gland.

Reproductive System (Figure 8). Large quantities of gonad fill the posterior portion of the specimen. The female gland mass is large and consists predominantly of the mucous gland with smaller albumen and membrane glands. The ampulla is large and bulbous, and it branches to the oviduct and the prostatic portion of the vas deferens. The oviduct connects to a small, nodulose receptaculum seminis. A second duct extends from near the base of the receptaculum seminis and joins the female glands near the albumen gland. The second branch of the ampulla connects to the vas deferens. The proximal portion is prostatic with the prostate being convoluted and small. The convoluted prostate joins a small, conical shaped, and unarmed penial bulb.

Buccal Armature. The jaws are thin and coriaceous, slightly elongating posteriorly. There are at least seven pointed, and uniformly sized small denticles situated along the masticatory border of each jaw (Fig. 5E, F). The radula has a formula of $21 \times 0.1 .0$. The teeth (Fig. 6C, D) are triangular in shape leading to a long and pointed primary cusp. Near the apex of each cusp, on the ventral side, is a triangle-shaped denticle, which 
gives the cusp a nearly bifid appearance. The rib on the ventral side of each tooth extends from the posterior of the tooth to the middle of the cusp. Denticulation extends along the margin from the base of the tooth nearly to the apex. The number of denticles varies between 14-16 per radular tooth. The denticles are slightly elongated with well-separated points that reach slightly under the edge of the tooth. Denticles are defined and wellseparated for the entire length of the tooth.

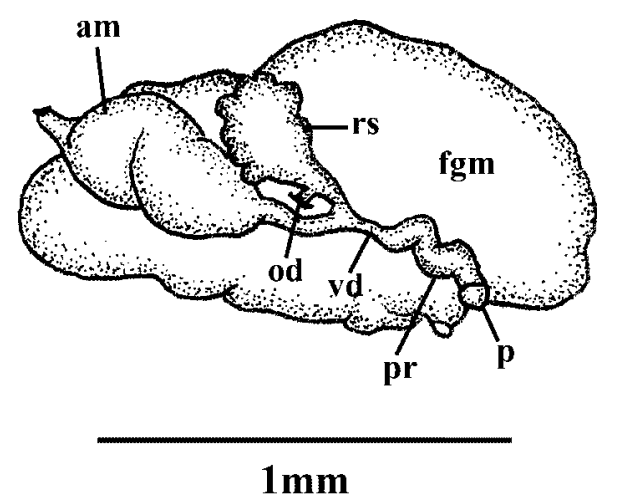

FIGURE 8. Reproductive system of Phyllodesmium karenae n. sp. Abbreviations: am-ampulla, rs-receptaculum seminis, od-oviduct, vd—vas deferens, $\mathrm{p}$ - penial papilla, $\mathrm{pr}$-prostate, al—albumen gland, mu—mucous gland, me-membrane gland, fgm-female gland.

Remarks. Of the previously described species of Phyllodesmium, there are only four, P. horridum (Macnae, 1954), P. opalescens Rudman, 1991, P. sp. 2 Moore \& Gosliner, in press and P. sp. 1 Moore \& Gosliner, in press, that have undivided digestive tissue within the cerata. Because P. karenae has relatively straight digestive tissue within the cerata, and is predominantly transparent, it is superficially most similar to P. opalescens. However, P. karenae has no opaque white markings on the dorsum, distinguishing it from $P$. opalescens as well as the other mentioned species. In addition, the radular cusps have a unique denticle located on the ventral part of each pointed tip, which has not been seen in any other species of Phyllodesmium. It is possible that this is variation, or an individual aberration seen within one of the other species, however in all documented accounts of dental structures seen in species of Phyllodesmium, this has never been noted. The small prostate and penis, along with the bulbous ampulla, further distinguish it from the other externally similar species, which have comparatively large prostate glands and penial papillae (Moore \& Gosliner in press). The fact that the female glands are large and fully developed indicates the specimen is reproductively mature, although it is possible that the specimen was not fully grown. Comparison with additional material when it becomes available would be highly desirable.

\section{Revised phylogenetic analysis}

The addition of two specimens of Phyllodesmium jakobsenae allowed a comparison between the previously mentioned P. sp. 3 (Moore \& Gosliner in press) and P. jakobsenae. Upon concluding that they were indeed the same species, $P$. sp. 3 was eliminated from the morphological phylogenetic analysis. However, the discovery of $P$. karenae, and the addition of three more described species of Phyllodesmium, warranted the addition of these taxa to the analysis. Phyllodesmium pinnatum and $P$. tuberculatum were already included in the analysis from Moore \& Gosliner (in press) (named P. sp. 1 and $P$. sp. 2 respectively). With the addition of $P$. karenae, P. lizardensis, $P$. lembehensis, and P. koehleri, and the removal of $P$. sp. 3 , the phylogeny now includes 26 species of Phyllodesmium (Table 1) and 32 characters. The characters and their states are listed below. 


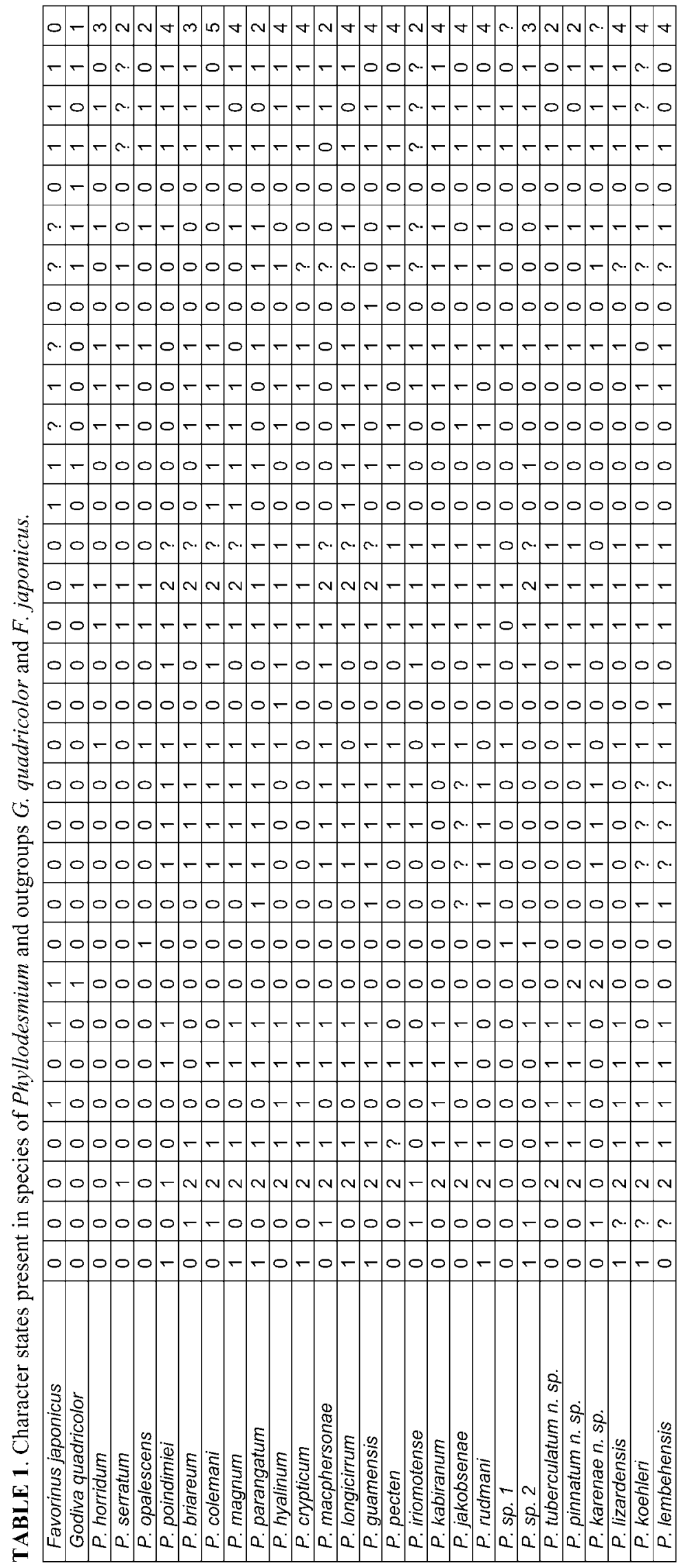


Characters and their states were as follows:

1. Body size: Refers to the overall length of the animal. A distinct gap appears to be evident between species that are smaller than $40 \mathrm{~mm}$ and those that are usually $50-100 \mathrm{~mm}$ in length. $0=$ Less than $40 \mathrm{~mm} ; 1=$ $40 \mathrm{~mm}$ or greater.

2. Foot width: Refers to the width of the foot in relation to the mantle and body. $0=$ wider than mantle; $1=$ the same width as, or narrower than the mantle.

3. Digestive gland: Refers to the degree of ramification in the duct of the cerata. The unbranched state is suspected to be the plesiomorphic state (Rudman 1991). $0=$ unbranched; $1=$ branched; $2=$ secondarily branched or further ramified.

4. Zooxanthellae: Refers to the presence or absence of zooxanthellae in digestive diverticula. The absence of zooxanthellae is suspected to be the plesiomorphic state (Rudman 1991). $0=$ absent; $1=$ present.

5. Ceratal texture: Refers to the texture of the external ceratal surface. $0=$ smooth; $1=$ nodulose, with distinct tubercles or papillae.

6. Ceratal shape: Refers to the shape of an individual ceras. $0=$ cylindrical; $1=$ flattened.

7. Ceratal apex: Refers to the shape of the tips of the cerata (based on comparisons of many photos of living animals in varied states of activity). Species listed as having curved or curled ceratal apices consistently exhibit this arrangement. $0=$ straight; $1=$ curved or curled.

8. Cnidosac: Refers to the presence or absence of a functional cnidosac. Presence of a functional cnidosac is suspected to be the plesiomorphic state (Rudman 1991). $0=$ present and non-functional; $1=$ present and functional; 2 = absent.

9. Shape of digestive gland duct: Refers to the presence or absence of undulation in the digestive diverticula of the cerata. $0=$ straight; $1=$ undulating.

10. Precardiac cerata: Refers to the shape of the anterior-most ceratal grouping. Arch-shaped ceratal groups are suspected to be the plesiomorphic state (Rudman 1991). $0=$ arch-shaped; $1=$ not arch-shaped.

11. Postcardiac cerata: Refers to the shape of the first postcardiac ceratal grouping. Arch-shaped ceratal groups are suspected to be the plesiomorphic state (Rudman 1991). $0=$ arch-shaped; $1=$ not arch-shaped.

12. Second group of cerata: Refers to the shape of the second postcardiac ceratal grouping. Arch-shaped ceratal groups are suspected to be the plesiomorphic state (Rudman 1991). $0=$ arch-shaped; $1=$ not archshaped.

13. Third group of cerata: Refers to the shape of the third postcardiac ceratal grouping. Arch-shaped ceratal groups are suspected to be the plesiomorphic state (Rudman 1991). $0=$ arch-shaped; $1=$ not arch-shaped.

14. Anterior foot corners: Refers to the shape of the anterior foot corners. $0=$ moderately tentacular or tentacular; $1=$ not tentacular.

15. *Anus position: Refers to the location of the anus (*this character was uninformative as it is autapomorphic for $P$. hyalinum). $0=$ within ceratal grouping; $1=$ dorsal to ceratal grouping.

16. Rhinophore size: Refers to the length of the rhinophores. Species that have rhinophores that are as long as or longer than the oral tentacles are considered to be greatly extended. $0=$ moderately long; $1=$ greatly extended.

17. Rhinophore surface: Refers to the texture on the surface of the rhinophores. $0=$ ornamented; $1=$ smooth.

18. Masticatory border: Refers to the number of rows of denticles on the jaw plate. $0=$ many rows of denticles. 1 = one row of denticles. 2 = smooth (no rows).

19. Jaw denticles: Refers to the overall appearance of the jaw denticles. $0=$ uniform size, or evenly graded; 1 = obvious size gradient.

20. Radular denticles: Refers to the overall appearance of the radular denticles. $0=$ well developed; $1=$ reduced or absent.

21. Cusp of teeth: Refers to the location of denticles on the radular cusp. $0=$ denticulate nearly to apex; $1=$ denticulate only well below apex.

22. Arrangement of radular denticles: Refers to the spacing between radular denticles. $0=$ well separated; $1=$ congested. 
23. Length of radular denticles: Refers to the length of the radular denticles. $0=$ elongate, longer than wide; 1 $=$ short, width equal to or wider than length.

24. Tip of radular denticles: Refers to the shape of the tips of the radular denticles. $0=$ blunt; $1=$ pointed.

25. *Rows of radular denticles: Refers to the number of rows of radular denticles (*this character was uninformative as it is autapomorphic for P. guamensis Avila et al., 1998). $0=$ one; $1=$ two.

26. Base shape of teeth: Refers to the shape of the base of the radular cusps. $0=$ triangular; $1=$ horseshoeshaped.

27. Base limb length of teeth: Refers to the length of the base of the radular cusps. $0=$ longer than cuspidate portion bearing denticles; $1=$ shorter than cuspidate portion bearing denticles.

28. *Penial spine: Refers to the presence or absence of a penial spine (*this character was uninformative as it is autapomorphic for Godiva quadricolor (Barnard, 1927)). $0=$ absent; $1=$ present.

29. *Female gland shape: Refers to the overall shape of the female gland mass (*this character was uninformative as it is autapomorphic for P. macphersonae (Burn, 1962)). $0=$ elongate; $1=$ bulbous.

30. Penial papilla: Refers to the size of the penial papilla. $0=$ large, much wider than the vas deferens; $1=$ small, equal in width to vas deferens or narrower.

31. Prostate length: Refers to the length of the prostate. $0=$ long, generally consisting of two or more deep convolutions; $1=$ short, with one or no shallow convolutions.

32. Prey: Refers to the kind of prey consumed. $0=$ opisthobranch eggs; $1=$ hydroids/opisthobranchs; $2=$ octocorals generally; $3=$ only gorgonians; $4=$ only soft corals; $5=$ only stoloniferans.

Maximum parsimony analysis revealed seven most parsimonious trees with 116 steps. The consistency index was 0.302 and the retention index was 0.597 . The decay analysis and cladogram are shown in Figure 9.

\section{Discussion}

The phylogeny presented in this study has some notable differences and similarities compared to that from Moore \& Gosliner (in press). Generally, major clades like the xeniid-associated clade (denoted as "II"), which includes $P$. hyalinum, $P$. jakobsenae, $P$. crypticum, $P$. kabiranum Baba, $P$. pinnatum, $P$. tuberculatum, $P$. lizardensis, $P$. lembehensis, and $P$. koehleri still tend to cluster together. This is not surprising, as these animals are morphologically similar, and although the prey species for $P$. pinnatum is unknown, the external morphology of this species strongly suggests it is associated with a xeniid coral.

Once again, some anomalies are seen, such as the exclusion of $P$. rudmani and P. jakobsenae from the xeniid-associated clade, regardless of their obvious association with xeniid corals. This surprising arrangement is due to the fact that $P$. rudmani and $P$. jakobsenae lack nodular cerata and that $P$. rudmani has post cardiac cerata arranged in rows rather than arches. In addition, P. koehleri is included in this clade, despite its probable association with a different soft coral in the family Nephtheidae (Burghardt et al. 2008a). Based on the taxa known for this group, it would appear that association with xeniid corals has facilitated a great deal of speciation in this genus that reflects adaptive radiation. The location of $P$. koehleri, coupled with its likely association with a non-xeniid coral, suggests that this species has diverged trophically to exploit a new family of soft corals. Due to their remarkable mimicry and camouflage, many of the symbiotic species that are associated with xeniid and nephtheid corals are still being discovered (Burghardt et al. 2008a; present study). This is especially evident in the lack of resolution seen at this particular clade, suggesting there may likely be more cryptic, highly camouflaged species in this complex. The potential discovery of additional species within this group, as well as the use of molecular characters, may provide more resolution in this part of the phylogeny.

Another similarity from Moore \& Gosliner (in press) is that symbiotic species generally still appear more derived morphologically than non-symbiotic species (non-symbiotic species are denoted as "A"). The basal part of the tree, which includes P. sp. 1, P. sp. 2, P. opalescens, P. horridum, and P. serratum (Baba, 1949), was 
also seen in Moore \& Gosliner (in press), but now includes P. karenae and P. iriomotense Baba, 1991. It is reasonable that $P$. karenae is located in this position as it has no zooxanthellae and no branching of the

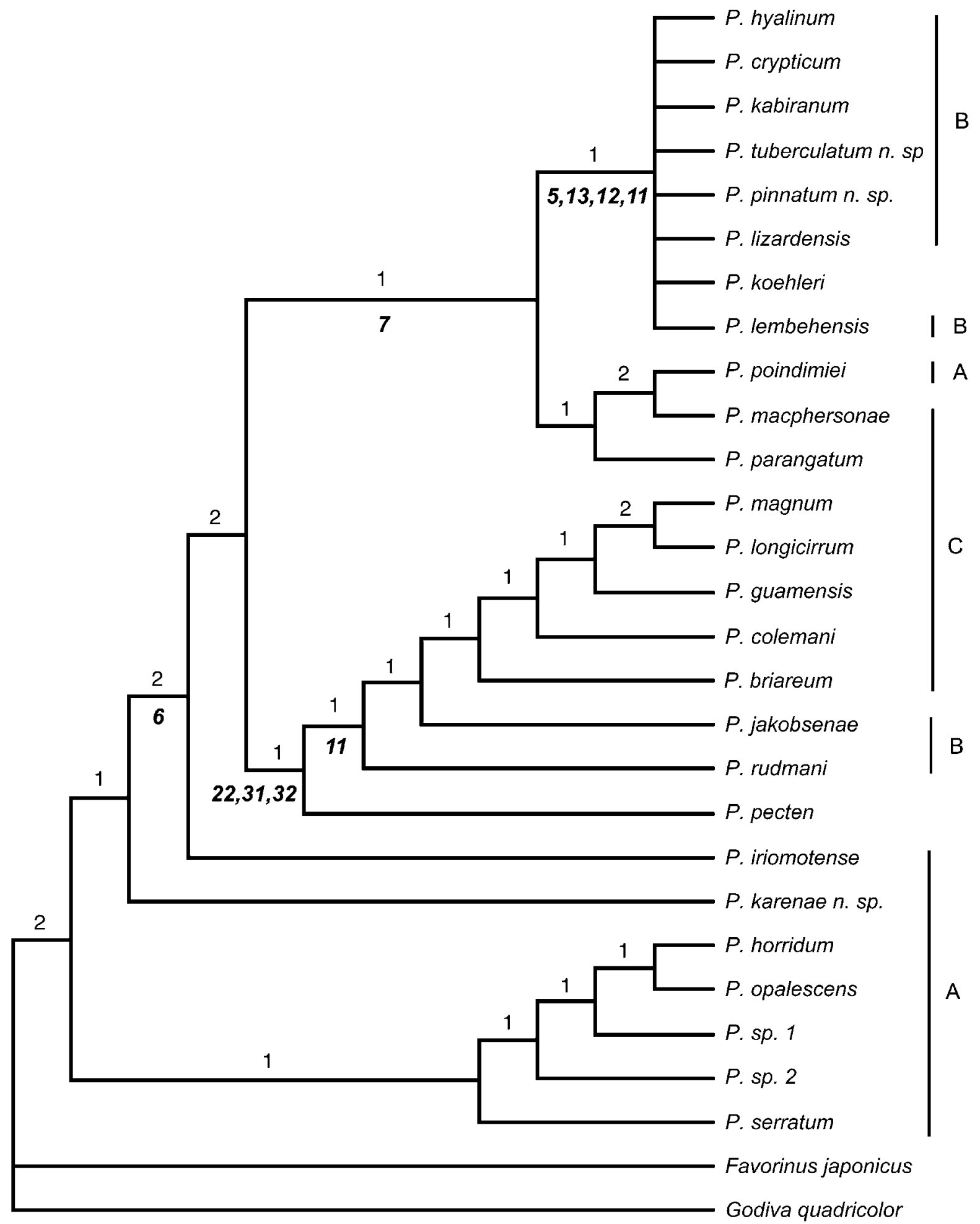

FIGURE 9. Strict consensus of 7 most parsimonious trees. $\mathrm{L}=116, \mathrm{CI}=0.302, \mathrm{RI}=0.597$. Numbers above branches are decay analysis values, key character synapomorphies are indicated in italics. Key synapomorphies include: 6-ceratal shape flattened, 7-ceratal apex curved, 22-radular denticles congested, 31-prostate short, 32-prey soft corals only, 11-post cardiac cerata not arch-shaped, 5-ceratal texture nodulose, 12-second group of cerata not archshaped, 13-third group of cerata not arch-shaped. 
digestive gland in the cerata. The placement of $P$. iriomotense in a mid-basal location also seems reasonable due to the obvious branching in the digestive gland of the cerata, but lack of zooxanthellae. In this part of the tree, $P$. iriomotense appears to be a bridge between the non-symbiotic species with no digestive gland branching, and the symbiotic species that have digestive gland branching. Once again, P. magnum Rudman, 1991 and $P$. longicirrum Bergh, 1905 cluster together among some of the most highly derived symbiotic species with many morphological modifications (denoted as "C"), including P. briareum (Bergh, 1896) $P$. colemani Rudman, 1991, and P. macphersonae (Burn, 1962). Most interesting in this clade is $P$. poindimiei (Risbec, 1928), which has moved into one of the most derived positions in the tree. This is somewhat puzzling due to the lack of symbiosis in this animal. The difference in placement between $P$. poindimiei and $P$. iriomotense is also somewhat puzzling as they have similar derived ceratal branching morphology but lack zooxanthellae. It appears as though the phylogenetic placement of $P$. poindimiei and $P$. iriomotense might be critically important for understanding the evolution of symbiosis in this group.

Despite important additions of new species to the morphological phylogeny, support values are still low at most clades and consistency and retention indices in this tree remain sub-optimal. The monophyly of Phyllodesmium is moderately supported (decay value of 2), but this is not highly robust. Adding more outgroup taxa to the analysis will help to determine true outgroup relationships and test the monophyly of the genus. In addition, including more undescribed taxa, as well as new morphological characters based on histology or additional organ systems will likely improve the tree, but the problem of conserved and ambiguous morphological characters, as well as highly cryptic species, could continue to be problematic. Morphological methods alone may not be sufficient for unraveling the evolutionary history of this group and molecular analyses should be employed to enhance the confidence of further phylogenetic analyses.

\section{Acknowledgements}

This research has been funded by the National Science Foundation PEET (DEB 0329054) Phylogeny of the Nudibranchia and the California Academy of Sciences Graduate Assistantship Program in Education. We thank our colleagues at the Philippines Bureau of Fisheries and Aquatic Resources for their assistance with logistics and in the field, as well as providing us with the necessary permits for collection and exportation of specimens. The assistance of Ludivina Labe, and Val Borja was particularly important. We also thank Peri Paleracio, dive guide at Club Ocellaris Dive Resort, for his assistance in locating critical specimens.

\section{References}

Avila, C., Ballesteros, M., Slattery, M., Starmer, J. \& Paul, V. J. (1998) Phyllodesmium guamensis (Nudibranchia: Aeolidoidea), a new species from Guam (Micronesia). Journal of Molluscan Studies, 64, 147-160.

Baba, K. (1949) Opisthobranchia of Sagami Bay collected by His Majesty The Emperor of Japan. Iwanami Shoten, Tokyo.

Baba, K. (1991) Taxonomical study on some species of the genus Phyllodesmium from Cape Murotomisaki, Shikoku, and Okinawa Province, southern Japan (Nudibranchia: Facelinidae). Venus, Japanese Journal of Malacology, 50, $109-124$.

Barnard, K. (1927) South African nudibranch Mollusca, with descriptions of new species, and a note on some specimens from Tristan d'Acunha. Annals of the South African Museum, 25, 171-215.

Bergh, R. (1896) Eolidiens d'Amboine. Revue Suisse de Zoologie et Annales de Musée d'Histoire Naturelle de Geneve, 4, $385-394$.

Bergh, R. (1905) Die Opisthobranchiata der Siboga-Expedition. Siboga Expediton Monographie, 50, pp. 1-248.

Burghardt, I., Evertsen, J., Johnsen, G. \& Wägele, H. (2005) Solar powered seaslugs - mutualistic symbiosis of aeolid Nudibranchia (Mollusca, Gastropoda, Opisthobranchia) with Symbiodinium. Symbiosis, 38, 227-250.

Burghardt, I., Schrödl, M. \& Wägele, H. (2008a) Three new solar powered species of the genus Phyllodesmium Ehrenberg, 1831 (Mollusca: Nudibranchia: Aeolidoidea) from the tropical Indopacific with analysis of their photosynthetic activity and notes on biology. Journal of Molluscan Studies, 74, 277-292. 
Burghardt, I., Stemmer, K. \& Wägele, H. (2008b) Symbiosis between Symbiodinium (Dinophyceae) and different taxa of Nudibranchia (Mollusca: Gastropoda) with analyses of longterm retention. Organisms, Diversity and Evolution, 8, 66-76.

Burghardt, I. \& Wägele, H. (2004) A new solar powered species of the genus Phyllodesmium Ehrenberg, 1831 (Mollusca: Nudibranchia: Aeolidoidea) from Indonesia with analysis of its photosynthetic activity and notes on biology. Zootaxa, 596, 1-18.

Burghardt, I. \& Wägele, H. (2006) Interspecific differences in the efficiency and photosynthetic characteristics of the symbiosis of "solarpowered" Nudibranchia (Mollusca: Gastropoda) with zooxanthellae. Records of the Western Australian Museum, Supplement 69, 1-9.

Burn, R. (1962) Descriptions of Victorian nudibranchiate Mollusca, with a comprehensive review of the Eolidacea. Memoirs of the National Museum, Melbourne, 25,:95-128.

Edmunds, M. (1966) Protective mechanisms in the Eolidacea (Mollusca, Nudibranchia). Journal of the Linnean Society (Zoology), 46, 27-71, pls. 1-4.

Ehrenberg, C. G. (1831) Symbolae physicae seu icones et descriptiones animalium evertebratorum sepositis insectis quae ex itinere per Africam borealem et Asiam Occidentalem-novae aut illustratae redierunt. Decas 1 Mollusca.

Gosliner, T. M. (2001) Aposematic coloration and mimicry in opisthobranch mollusks: new phylogenetic and experimental data. Bollettino Malacologio, 37, 163-170.

Gosliner, T. \& Behrens, D.W. (1990) Special resemblance, aposematic coloration and mimicry in opisthobranch gastropods. In: M. Wicksten (Ed). Adaptive Significance of Color in Invertebrates. Texas A. \& M. University Press, College Station, pp. 127-138.

Gosliner, T., Behrens, D.W \& Valdés, Á. (2008) Indo-Pacific nudibranchs and sea slugs: A field guide to the world's most diverse fauna. Sea Challengers and California Academy of Sciences, Gig Harbor, WA and San Francisco, CA, $426 \mathrm{pp}$.

Kempf, S.C. (1984) Symbiosis between the zooxanthella Symbiodinium (=Gymnodinium) microadriaticum (Freudenthal) and four species of nudibranchs. Biological Bulletin, 166, 110-126.

Kepner, W. (1943) The manipulation of the nematocysts of Pennaria tiarella by Aeolis pilata. Journal of Morphology, $73,297-310$.

Macnae, W. (1954) On some eolidacean nudibranchiate molluscs from South Africa. Annals of the Natal Museum, 13, 150, pls. 1-2.

Maddison, D.R. \& Maddison, W.P. (2005) MacClade 4. Sinauer Associates, Sunderland, Massachusetts.

Moore, E. \& Gosliner, T. (In press) Additions to the genus Phyllodesmium, with a phylogenetic analysis and its implications to the evolution of symbiosis. The Veliger.

Risbec, J. (1928) Contribution a l'etude des nudibranches Néo-Calédoniens. Faune des Colonies Française, 2, 1-328, pls. $1-12$.

Rudman, W.B. (1981) The anatomy and biology of alcyonarian-feeding aeolid opisthobranch mollusks and their development of symbiosis with zooxanthellae. Zoological Journal of the Linnean Society, 72, 219-262.

Rudman, W.B. (1991) Further studies on the taxonomy and biology of the octocoral feeding genus Phyllodesmium Ehrenberg, 1831 (Nudibranchia: Aeolidoidea). Journal of Molluscan Studies, 57, 167-203.

Swofford, D.L. (2002) PAUP*. Phylogenetic analysis using parsimony (*and other methods), version 4.0. Sinauer Associates, Sunderland, Massachusetts. 